\title{
COLOR CHARTS
}

This bureau does not issue any general color chart showing samples representative of the various colors. The following charts showing samples of colors for certain specific purposes are issued or used by some branch of the U.S. Government.

United States Army Color Card, issued by the Textile Color Card. Association of the United States, Inc., 200 Madison Avenue, New York, N. Y. This card shows 18 U. S. Army colors standardized for the different arms and services. It has been aporoved and accepted by the Quartemaster General as being in accord with the standards on file in that office. The samples are inch by halfinch rectangles of silk. This card is used in the purchase of textile materials by the Army.

Supplement to $\mathbb{N o} \cdot 3-1$ and revisions thereof of the U.S. Army General Specification for Paint and Related Materials, issued by the Office of the Guartermaster General, Washington, D.C. This card shows 24 colors, identified by name and number. The samples are stiff paper, $1-1 / 2$ by $5 / 8$ inch rectangles, with glossy finish. This card is used in the purchase of paint and related materials by the Army.

Aircraft Color Cards, issued by the Bureau of Aeronautics, Navy Department. This is a group of twelve colors, seven of which are irmy-Navy standards, and five, Special Navy standards. The samples are 4 by 6 -inch panels of cardboard having the semi-glossy finish due to paint ap plied by spray. They are used in the purchase of finishing materials for aircraft.

Color for School Furniture, Simplified Practice Recommendation RII1-30, obtainable from the Superintendent of Documents, Vashington, D.C., price 5 cents. This publication contains a printed representation of the standard school furniture brown adopted by a conference of producers, distrioutors and users of school furniture. The printed reproduction of this color is intended only to indicate the color selected; stained blocks of wood are the actual standards used.

Colors for Sanitary Ware, Commercial Standard CS30-3I, obtainable from the Superintendent of Documents, Washingt on, D.C., price 20 cents. This publication contains a printed representation of 6 standara colors adopted by a conference or producers, ảistributors and users of sanitary ware, includine plumoing fixtures and allied products made of vitreous china, porcelain (all-clay), enameled iron, retals, wood, or glass. The printed reproductions of these colors are intended only to indicate the colors selected; vitreous samples are used as the actual standarảs. 

Color System for Founary Patterns of Wood, Comnercial Standard CS19-32, obtainable from Superintendent of Documents, Washington, D. C., price 10 cents. This publication contains a printed representation of three colors to be used in marking patterns in order to indicate which surfaces are to be left unfinished, which machined, and so forth. Some variations of these colors are permissible within reasonable limitations.

The following publications contain color charts of use for general purposes:

Color Standards and Color Nomenclature, by Robert Ridgway, A. Fioen and Company, Baltimore, IId., 1912. Contains approximately 1,000 named color samples, each sample being a matt or nearly matt paper rectangle one-half by one inch in size. The samples are arranged on each page with light samples at the top of the page grading down from white through eight steps to black at the bottom. iach column shows colors of constant hue, the hue circle being represented by 35 such columns. The first series of hue columns gives samples whose colors are of maximal saturation, then there are four similar series, each showing colors progressively dulled by the addition of gray. The color names are listed alphabetically and the corresponding sample located by giving the plate number and an approximate hue, saturation, and brightness notation. These charts have been widely used for the specification of the colors of flowers, insects, and birds.

liunsell Book of Color, by the liunsell Color Company, Hoffman Brothers, Baltimore, Md. 1929, obtainable from Universal Color Standards, Inc., $500 \mathrm{~N}$. Ćalvert Street, Baltimore, Md. Two editions, standard and abridged, each giving approximately 100 different color samples. The standard edition consists of charts, one for each of ten different hues, showing colors varying in brilliance (Niunsell term: value) and saturation (lifunsell term: chroma); there are also charts, one for each of eight chromas, showing colors varying in hue and value; charts, one for each of six values, showing colors varying in hue and chroma; and two charts shoving altogether 20 hues at maximal chroma for each of eight values. The samples are rectangles of matt or nearly matt paper, $5 / 8$ by $7 / 8$ inches, except for those of the constant-value charts which are $1 / 2 \mathrm{by} 5 / 8$ inches. The abrided edition consists of 20 constant hue charts made up of $1 / 2$ by $5 / 3$ inch samples. In both editions the samples of the constant-hue charts are arranged in rows and columns, the samples in any one row being equally bricht, and the samples in any one column being equaliy saturated. The colors progress from very light at the top of each chart to very dark at the bottom by steps which are visually equal; and they progress from achronatic colors at the left side of each chart to saturated colors at the right by steps which are also visually equal. Each sample is identified by three symbols -- the first indicating hue, the second, value, and the third, chrona. These charts, because of the logical arrangement of the samples and the fact that the color differences between successive samples are visually equal, have a wide application; they are used in color education, in the setting of color tolerances, and as practical color standards. 

A Dictionary of Color, by A. Maerz and M. Rea Paul, McGrawHill Book Company, Inc., 370 Seventh Avenue, ivew York, N. Y. Contains approximately 7,000 different color samples printed on semiglossy paper, about 6,000 of which are $1 / 2$ by $5 / 8$ inch, rectanges, and about 1,000 of the darker of which are $1-1 / 16$ by $5 / 8$ inch rectangles. The hue circle is covered in 8 intervals, each interval by a series of 8 charts each, the hues within each interval being obtaired by mixtures of the pigments representing the extremes of the interval. The rirst chart in a series shows one extreme pignent at the upper right-hand corner, the other at the lower left. The upper-left corner is white, the lower right a mixture in about equal proportions of the two extreme.pigments. The samples intermediate on the chart represent colors which are intermediate, and the color steps between successive samples have been adjusted so that they are; in general, about equal. Each chart, therefore, shows a progression of hues from the upper-right to the lower-left corner, while the hues of the samples along the lines parallel to the other diagonal are nearly constant. The second chart in a series differs from the first bY admixture of a gray ink; the third chart corresponds to admixture of a darker gray ink; and so on down to the eighth chart which shows very dark colors. An alphabetical list of about 4,000 color names is given together with a key by means of which each corresponding sample may be found in the charts. These samples are also identified by name in the charts, themselves. The large number of the samples makes the steps between successive colors so small that interpolation is often not necessary. On this account they may be used conveniently as practical color standards in nearly every field. Furthernore, the scholarsinip and thoroughness of treatment have given this lork a wide reputation as the foremost authority on color names.

Standard and Seasonal Color Cards, issued by the Textile Color Card Association of the United States, Inc., 200 Madison Averue, New York, N. Y. The samples are inch by one-half inch rectangles of silk. Each sample is identified by name and cable number. The standard cards are revised only infrequently and show about 200 staple colors. Two seasonal cards are issued every year, a spring card and a fall card; they supplement the standard card. These cards are widely used in the textile and allied industries, and are there the accepted authority. 


